\section{Theragnostic ultrasound using microbubbles in the treatment of prostate cancer}

\author{
Hak Jong Lee ${ }^{1,2,3}$, Young II Yoon ${ }^{1,3}$, Yun Jung Bae $e^{1,2}$ \\ 1 Department of Radiology, Seoul National University Bundang Hospital, Seongnam; \\ ${ }^{2}$ Department of Radiology, Seoul National University College of Medicine, Seoul; \\ ${ }^{3}$ Program in Nanoscience and Technology, Department of Transdisciplinary Studies, Graduate \\ School of Convergence Science and Technology, Seoul National University, Seoul, Korea
}

The use of gas-filled microbubbles in perfusion monitoring as intravascular ultrasound contrast agents has recently become more common. Additionally, microbubbles are employed as carriers of pharmaceutical substances or genes. Microbubbles have great potential to improve the delivery of therapeutic materials into cells and to modify vascular permeability, causing increased extravasation of drugs and drug carriers. Prostate cancer is the most common neoplasm in Europe and America, with an incidence twice to three times that of lung and colorectal cancer. Its incidence is still rising in Asian countries, including Japan and Korea. In this review, we present current strategies regarding the synthesis of microbubbles with targeted ligands on their surfaces, with a focus on prostate cancer.

Keywords: Prostate; Microbubbles; Ultrasonography

\section{Introduction}

Several key concepts encapsulate the future of medicine, including early diagnosis using molecular imaging, personalized medicine using genetic data, minimally invasive surgery with advanced surgical techniques and medical devices, and image-guided therapy using imaging modalities and newly developed therapeutic materials.

The most common imaging technique is X-rays. Ultrasonography is the second most commonly used imaging technique in clinical contexts. It is non-invasive, widely available, portable, relatively inexpensive, and allows real-time imaging without the use of ionizing radiation [1-4].

Ultrasonography has become a cornerstone for diagnosis and patient management. A new field, known as image-guided therapeutics delivery, harnesses the vast potential of ultrasound technologies for treatment delivery, and promises to fulfill the vision of personalized medicine [2]. Many researchers are trying to create complexes that target specific cells and deliver therapeutic materials into those cells. The prostate is a very good candidate for exploring these possibilities, especially using ultrasonography.

Prostate cancer is one of the important diseases in the world. It is the most common neoplasm in

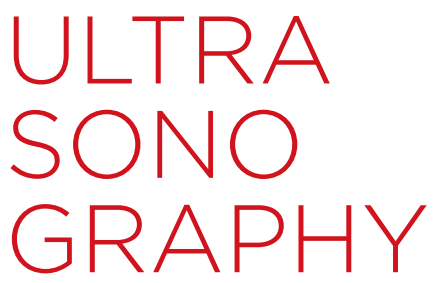

REVIEW ARTICLE

http://dx.doi.org/10.14366/usg. 16006 pISSN: 2288-5919 • elSSN: 2288-5943 Ultrasonography 2016;35:309-317

Received: February 5, 2016

Revised: April 14, 2016

Accepted: April 14, 2016

Correspondence to: Hak Jong Lee, MD, PhD, Department of Radiology, Seoul National University Bundang Hospital, 82 Gumi-ro 173 beon-gil, Bundang-gu, Seongnam 13620, Korea

Tel. +82-31-787-7605

Fax. +82-31-787-4011

E-mail: hakjlee@snu.ac.kr

This is an Open Access article distributed under the terms of the Creative Commons Attribution NonCommercial License (http://creativecommons.org/ licenses/by-nc/3.0/) which permits unrestricted noncommercial use, distribution, and reproduction in any medium, provided the original work is properly cited.

Copyright (C) 2016 Korean Society of Ultrasound in Medicine (KSUM)

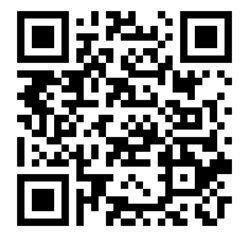

How to cite this article:

Lee HJ, Yoon YI, Bae YJ. Theragnostic ultrasound using microbubbles in the treatment of prostate cancer. Ultrasonography. 2016 0ct;35(4):309-317. 
Europe and America, with an incidence two to three times that of lung and colorectal cancer [5]. Its incidence is still rising in Asian countries, including Japan and Korea. The screening, detection, and diagnosis of prostate cancer are currently based on serum prostatespecific antigen levels, digital rectal examinations, and transrectal ultrasound-guided systematic biopsies [5].

Ultrasound plays a major role in the diagnosis of prostate cancer. With advances in research into targeted imaging, many studies are being performed to detect early prostate cancer through targeted imaging. This review describes the usage and design of ultrasoundcontrast complexes for visualizing prostate cancer and for delivering therapeutic materials in the context of prostate cancer management.

\section{Microbubbles}

The most commonly used ultrasound molecular-imaging contrast agents are microbubbles, which range in size from 1 to $8 \mu \mathrm{m}$. They consist of a gas core stabilized by a surrounding shell made from materials such as phospholipids, biocompatible polymers, or proteins [1-4]. In a previous study, we prepared microbubbles with a spherical shape and a mean diameter of about $2 \mu \mathrm{m}$, and a narrow size distribution (Fig. 1). The inner gases used in microbubbles are ordinary air, nitrogen, or biologically inert heavy gases, including perfluoropropane, perfluorobutane, perfluorohexane, or sulfur hexafluoride [1-5]. Heavy gases usually show better stability and lead to a longer blood half-life of the microbubbles. Yoon et al. [6] and Moon et al. [7] described the preparation and function of microbubbles in detail. We experimentally confirmed the echogenicity of the microbubbles. Compared with phosphatebuffered saline (Fig. 2A), microbubbles show high echogenicity,

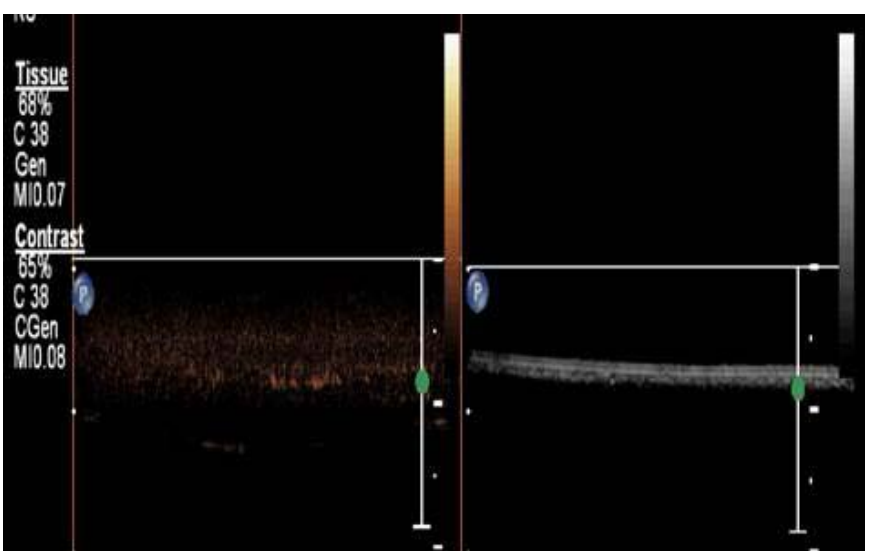

A

Fig. 2. Ultrasound phantom images of phosphate buffer saline (PBS) and microbubbles.

Compared with PBS (A), the microbubbles (B) show high echogenicity and can therefore act as an ultrasound contrast agent (arrow). Approximately $2.6 \times 10^{8}$ microbubbles are present per milliliter.

which makes them useful as an ultrasound contrast agent (arrow in Fig. 2B). The synthesis of targeted microbubbles is not significantly different from the synthesis of non-targeted microbubbles, except for an additional process that adds binding ligands to the shell of the microbubbles.

The microbubbles can act as cavitation nuclei that carry drugs or genes to target cells, enabling site-targeted treatment [8-10]. Ultrasonography can facilitate microbubble-mediated delivery by inducing the collapse of the microbubbles, perforations in the cell membranes, and increasing the permeability of regional capillaries, thereby allowing large molecules to stream into the cells. This phenomenon, known as sonoporation, can enhance the intracellular delivery of drugs or genes in ultrasound microbubble-mediated

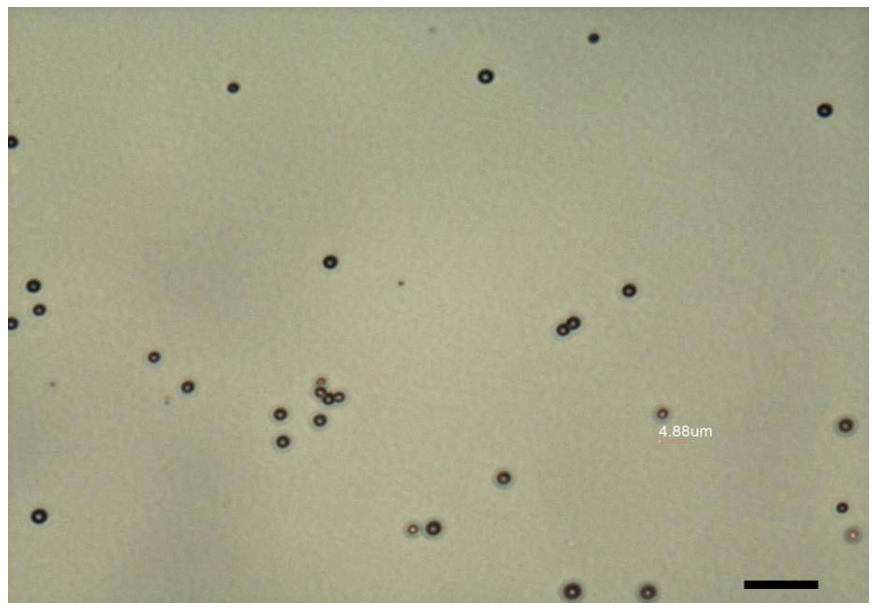

Fig. 1. Optical microscope image of microbubbles. The prepared microbubbles have a spherical shape with a mean diameter of approximately $2 \mu \mathrm{m}$ and a narrow size distribution (scale bar $=10$ $\mu \mathrm{m})$.

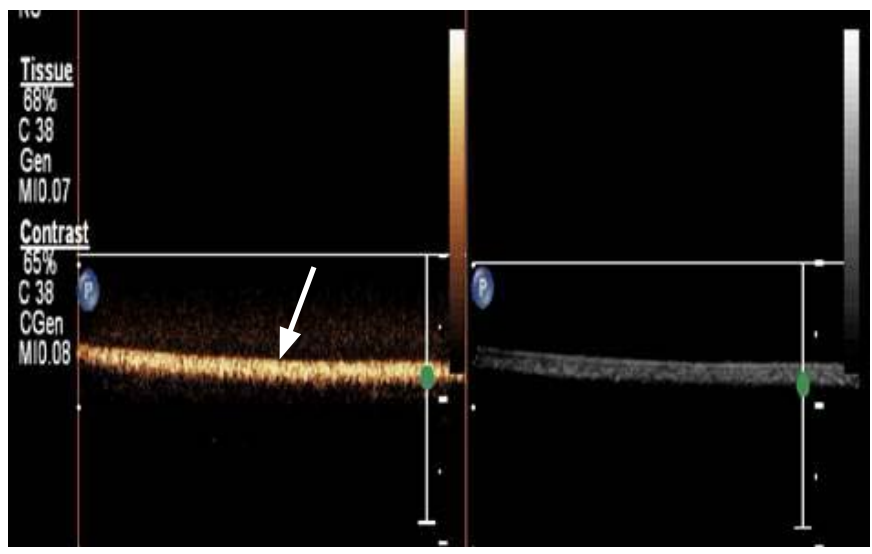

B 
delivery $[9,11]$. When the microbubbles are injected intravenously, the majority of microbubbles are cleared by the hepatic and splenic reticuloendothelial system (RES), with $95 \%$ of the microbubbles cleared from the blood pool after 30 minutes [12]. The gas contained within the microbubbles is removed from the body by exhalation [4].

Low mechanical index (MI) imaging (MI of 0.1 or less) allows the visualization of microbubbles as a contrast agent without destroying them due to nonlinear oscillations [13]. These asymmetric nonlinear oscillations result in the generation of harmonic (second harmonic and above) or subharmonic (half of the center frequency) echoes that can be leveraged to enhance the signal-to-noise ratio from the microbubbles in comparison to the surrounding tissue. These echoes can be visualized using a range of contrast imaging technologies, such as pulse inversion or amplitude modulation [14].

\section{Targeting Strategy}

Active and passive targeting strategies have been developed. Passive targeting takes advantage of enhanced permeability and retention [15-17]. However, this phenomenon, which has been primarily observed in subcutaneous xenograft mouse tumors, is often muted in other models, including orthotopic animal models in mice or larger species [17].

The other targeting strategy is active targeting. Several conjugation techniques exist to couple ligands to the bubbles. The targeting ligands include antibodies, peptides, and natural or engineered scaffolds, and they can be directly incorporated into the shell during or after the microbubble synthesis process [4]. In order to attach the ligands to the microbubble shell, a suitable reactive moiety, such as biotin, a carboxylate group, thiol, or maleimide, is attached to a shell-forming material component. The avidinbiotin interaction is among the strongest noncovalent bonds and is widely used in biomedical research and analytic techniques such as immunoassays (Fig. 3). However, foreign proteins such as avidins can cause an immune response, and this coupling scheme is therefore useful only in preclinical research. Antibodies have clinical limitations due to the immune response. In order to avoid this issue, antibodies must be adapted for use in humans.

PEGylation, using polyethylene glycol (PEG), has been used to create so-called stealthy agents and reduce RES clearance rates, but it can impair ligand-directed targeting due to steric interference. Moreover, PEG, once thought to be a benign surface modifier because it reduces complement activation, has been found to induce adaptive immune responses with repeated usage [18]. In active targeting, the homogeneous and highly restricted expression of tumor-associated antigens is critical to ensure the success of targeted immunotherapies. Much research is currently focused on the recognization of materials related to angiogenesis due to tumors and biomarkers specific to tumors.

\section{Vascular Endothelial Growth Factor Receptor Type 2}

Recently, the first targeted molecular ultrasound contrast agent has been designed and entered clinical trials in humans [19]. This contrast agent, known as BR55 (Bracco, Milano, Italy), consists of a gas core composed of a mixture of perfluorobutane and nitrogen, and is surrounded by a phospholipid shell with a mean diameter of $1.5 \mu \mathrm{m}[4,20,21]$. The ligand is attached at the kinase insert domain receptor (KDR; the human analog of vascular endothelial growth factor receptor type 2 [VEGFR2]). VEGFR2 is overexpressed in the neovasculature of many human cancer types, including prostate cancer, breast cancer, ovarian cancer, pancreatic cancer, and

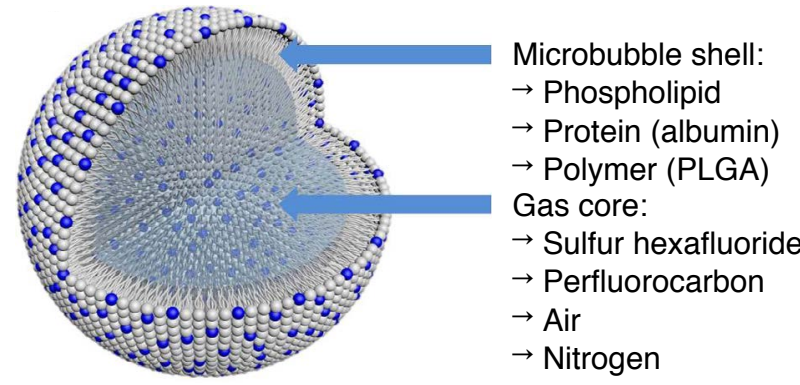

A

Fig. 3. Schematic diagram of microbubbles.

A. Microbubbles are microspheres with a shell composed of various materials and a core that can contain a range of gases depending on the purpose. B. Different types of ligands (e.g., antibodies, proteins, and peptides, etc.) can be attached non-covalently or covalently by using biotin/avidin, amine/amide, maleimide/thioether, or 2-(pridylthio)propionyl/disulfide onto the shell surface [4]. The blue color in the lipid diagram represents a functional group $\left(\mathrm{NH}_{2}\right.$ or $\left.\mathrm{SH}\right)$ that can bind with various types of ligands, and the grey color indicates membrane lipids. 
colorectal cancer.

\section{Prostate-Specific Membrane Antigen}

Prostate-specific membrane antigen (PSMA) is an attractive target for detecting primary and metastatic prostate cancer because its expression is elevated throughout all stages of the progression of prostate cancer, and it is highly restricted to prostate cells, with very low levels of expression detectable in other tissues [22]. PSMA, also known as folate hydrolase I, glutamate carboxypeptidase II, and $\mathrm{N}$-acetyl-L-aspartyl-L-glutamate peptidase I, is a 750-amino acid type II transmembrane glycoprotein that is primarily expressed in normal human prostate epithelium and is elevated in prostate cancer, including metastatic disease [23].

It has been reported that elevated levels of PSMA in patients with primary prostate cancer correlate with other traditional adverse prognostic factors and independently predict disease outcomes [24].

Since PSMA is expressed in all prostate cancers and its expression is further increased in poorly differentiated, metastatic, and hormone-refractory carcinomas, it is a very attractive target for the diagnosis, staging, and treatment of the disease [25-27].

Recently, an indium-111 radiolabeled anti-PSMA monoclonal antibody (Capromab Pendetide, Cytogen Corporation, Princeton, NJ, USA) has been used to detect soft-tissue metastasis and recurrence of prostate cancer. This antibody targets the intracellular domain of PSMA and is thought to bind mostly to the necrotic cells of prostate tumors [28]. More recently, Nawaz [29]. have developed and radiolabeled monoclonal antibodies that bind to the extracellular domain of PSMA, and these antibodies have entered into multiple clinical trials, including one exploring targeted radiotherapy for metastatic prostate cancer. Several PSMA monoclonal antibodies have been used as vehicles for the targeted delivery of cytotoxic agents, including radioactive isotopes, small molecules, and protein toxins [30-33].

Although monoclonal antibodies have potential as tumortargeting agents, their long circulating half-life and poor ability to penetrate tumors limit their effectiveness as diagnostic and therapeutic agents [34]. Due to these limitations, monoclonal antibodies have shown only limited clinical success to date, mostly in the treatment of blood-borne cancers, such as non-Hodgkin lymphoma [35].

Small molecules such as peptides, vitamins, and substrate analogs offer significant advantages over antibodies for targeting solid tumors [36]. They exhibit better tumor penetration than antibodies [37]. Since small molecules exhibit enhanced diffusibility into the extravascular space and faster blood clearance than antibodies, they show a lower background signal. Moreover, synthesizing analogs that exhibit diverse chemical properties may allow the binding affinity and pharmacokinetics to be altered. A series of smallmolecule PSMA inhibitors with high affinity (in the low nanomolar range) and selectivity also have been explored for the imaging of PSMA-positive prostate cancer cells [33,38-40].

\section{Human Epidermal Growth Factor Receptor 2}

Human epidermal growth factor receptor 2 (HER2) is associated with the expression of the ErbB-2, CD340, and p185 genes. The amplification or overexpression of ErbB-2 occurs in approximately $30 \%$ of breast cancers, as well as in other tumors. Since it is well known that some kinds of prostate cancer cells express HER2 [41], researchers are trying to target prostate cancer cells by conjugating anti-HER2 antibodies to microbubbles. In one such study, the intracellular uptake of the microbubble-anti-HER2 antibody complex was significantly higher in LNCaP cells, which express higher levels of HER2, than in PC-3 cells. This proved that microbubble complexes conjugated with anti-HER2 antibodies were capable of effectively targeting prostate cancer cells [41].

\section{Integrin}

Integrins consist of noncovalently associated $\alpha$ and $\beta$ subunits, and are cell surface receptors that primarily mediate the interactions of cells with components of the extracellular matrix. It has been well established that $\alpha v \beta 3$ integrin is usually expressed at low or undetectable levels in normal cells but can be highly elevated in most cancer cells and especially in prostate cancer cells [42-44]. This protein is known to contribute to the migration, proliferation, and survival of cancer cells. Moreover, $\alpha v \beta 3$ integrin is also involved in the pathogenesis of bone metastases [45] and has been found to play a crucial role in bone metastasis [46]. A drug delivery system conjugating Arg-Gly-Asp (RGD) peptides for targeting $\alpha v \beta 3$ integrin has been also documented in animal models of primary tumors $[44,47,48]$.

Several preclinical and clinical studies have been performed to image primary prostate cancer and/or metastasis using radiolabeled RGD peptides and analogs targeting integrin $\alpha v \beta 3$ for tumor angiogenesis imaging and tumor therapy $[44,49-53]$. $\alpha v \beta 3$ and GRPr are validated biomarkers present on the surfaces of most prostate cancer cells. Micro-positron emission tomography imaging investigations at 4 hours after injection produced high-quality and high-contrast whole-body images with minimal tracer present in surrounding collateral abdominal tissues. The high selectivity and retention of this tracer in tumor tissue suggest that a 67Cu radiolabeled agent of this type may also be useful in targeted radiotherapy for primary prostate cancer tumors and metastatic disease.

Furthermore, the results of the above study support those of 
previous studies published by other research groups, which have suggested radiolabeled antagonists to be preferable over agonists for the molecular imaging of human cancers.

\section{Delivery of Therapeutics}

While ultrasound is a well-established diagnostic imaging technique, its great potential to enhance drug delivery was only recognized in the late 1990s [52]. Since then, the ultrasound-mediated uptake of small drugs, proteins, and larger nanoparticles such as gene complexes or drug-loaded liposomes has been reported [5459]. Due to the compressibility of microbubbles, microbubbles can cavitate in an ultrasonic field. Cavitation is the alternating shrinking and expanding of the microbubbles according to the pressure phases of the ultrasound wave [60]. Cavitation produces backscatter of the ultrasound waves, thereby intensifying the reflected signal [61]. Since microbubbles amplify the biophysical effects of ultrasound waves, they are also essential for drug delivery using ultrasound. According to the ultrasound intensity, the cavitation of microbubbles may be classified as stable and inertial.

In stable cavitation, microbubbles show continuous low-amplitude oscillations, generating microstreams in the surrounding fluid. Our group has researched the in vivo echogenicity of microbubbles. A xenograft PC-3 tumor model was observed using a clinical ultrasound device. A post-contrast ultrasound image (arrows in Fig. 4B) shows definitively enhanced vascularity compared to before the contrast injection (Fig. 4A). Under higher ultrasound intensities, inertial cavitation occurs, with larger oscillations and eventually bursting of the microbubble. Inertial cavitation is accompanied by more violent phenomena, such as microjets and shock waves

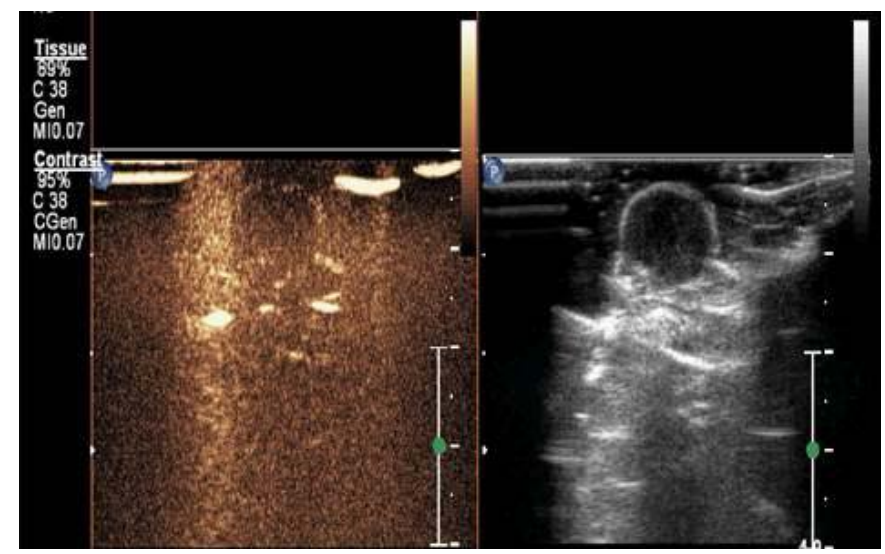

A

Fig. 4. In vivo results of a study on microbubbles.

The xenograft PC-3 tumor model was observed with a clinical ultrasound device (iU22 ultrasound scanner [Philips Healthcare, Bothell, WA, USA] equipped with a 5-12 MHz broadband linear transducer). A post-contrast ultrasound image (B) shows definitively enhanced vascularity (arrow) in comparison to before the contrast injection (A).

e-ultrasonography.org

Ultrasonography 35(4), October 2016

resulting in pore formation in the cell membrane, which is known as sonoporation [62]. In addition to sonoporation, enhanced endocytosis also contributes to ultrasound-mediated delivery. The two mechanisms in the ultrasound environment seem to depend on molecule size and the acoustic pressure used.

Although microbubble cavitation in ultrasonic fields has been studied extensively, the biophysical mechanisms leading to enhanced drug delivery are still a matter of debate. Sonoporation is generally accepted as the main mechanism through which drugs enter cells during ultrasound application. Scanning electron microscopy images have shown clear membrane disruptions after ultrasound exposure [63]. Moreover, several studies have demonstrated the uptake of cell-impermeable molecules when cells are exposed to ultrasound [59,64-66].

However, Meijering et al. [67] argued that in addition to pore formation, enhanced endocytosis also contributes to ultrasoundmediated delivery. According to their findings, molecule size determined the route of uptake, with endocytosis playing a greater role for larger molecules. Some other studies have confirmed that endocytosis is indeed involved in ultrasound-mediated uptake [59,68-71]. De Cock et al. [59] hypothesized that this discrepancy in the literature may be due to variations in the intensity levels that have been used in previous studies. In the first part of their study, they investigated whether the route of uptake (via pores or via endocytosis) was dependent on the acoustic pressure used. Moreover, the uptake of low- and high-molecular-weight dextrans was compared to evaluate the role of molecule size. In the second part of their study, they performed real-time confocal microscopy during ultrasound radiation to reveal microbubble-cell interactions. They concluded that low acoustic pressure enhanced uptake by

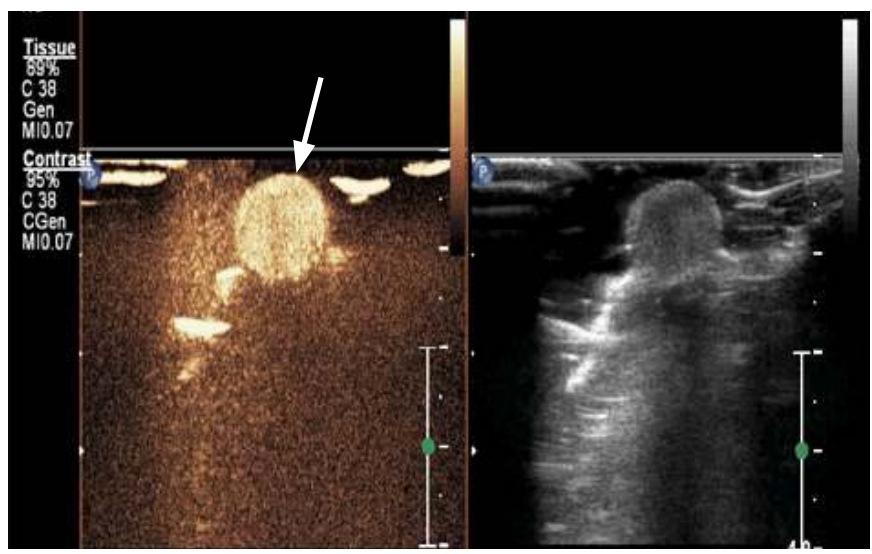

B 


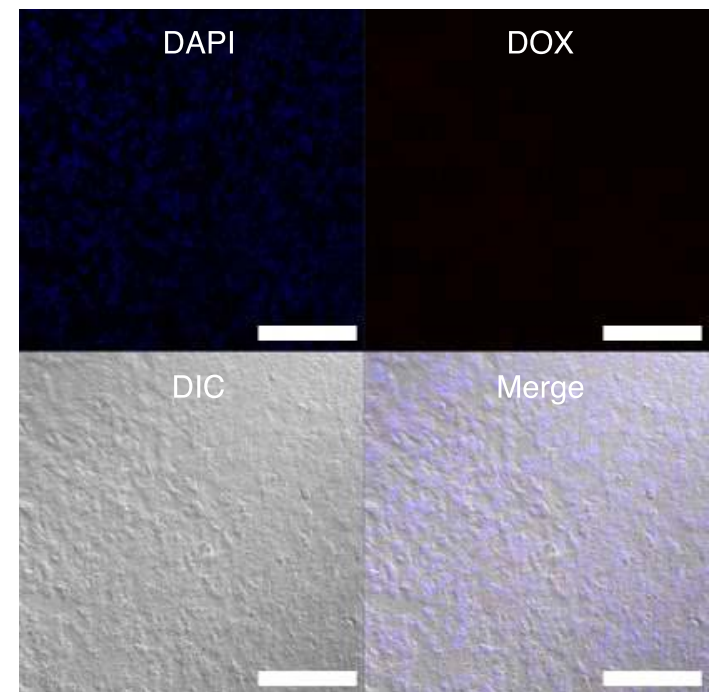

A

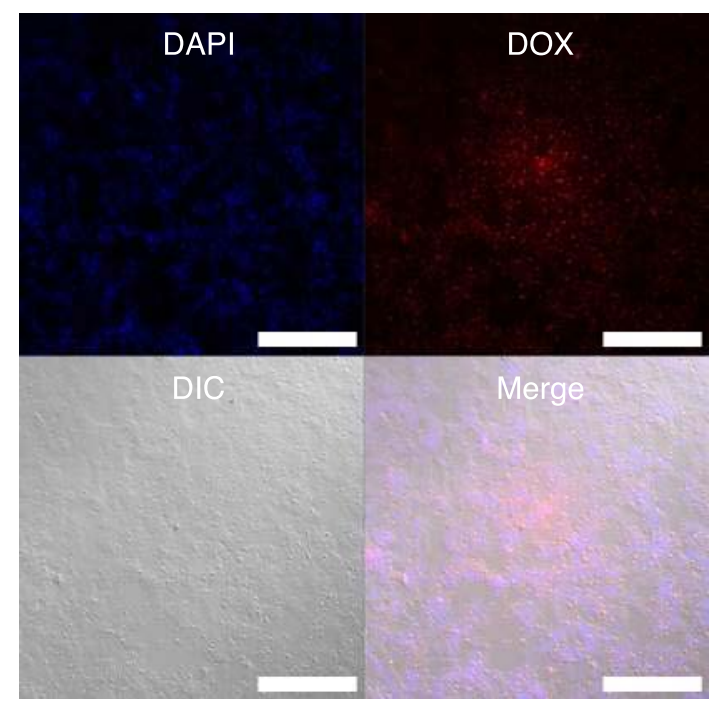

C

predominantly stimulating endocytosis, whereas high acoustic pressures led to uptake via membrane pores. The primary radiation force propelled microbubbles towards cells at a high velocity. Upon collision, pores were created in the cell membrane. When designing drug delivery experiments, these findings should be considered in order to select the optimal ultrasound settings [59].

Our group has researched the delivery effect of sonoporation in an in vivo model (Fig. 5). In order to confirm the delivery of anticancer drugs into tumor tissues within a xenograft PC-3 tumor model, a confocal laser scanning microscope was used for observation. Microbubbles with doxorubicin were injected via the tail vein, and then ultrasound treatment for delivery was performed using a sonoporator (Sonidel, Dublin, Ireland). Changing the treatment time from 5 minutes to 15 minutes increased the fluorescence intensity

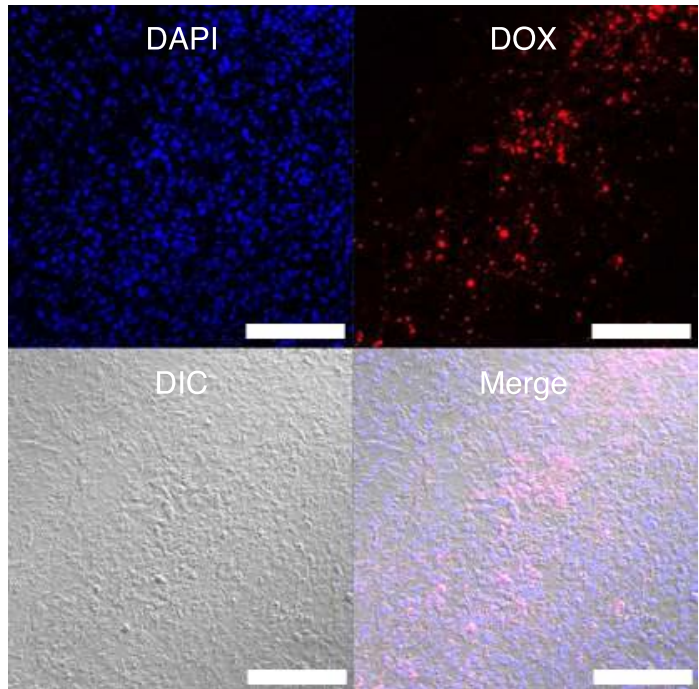

B

Fig. 5. In vivo study results of microbubbles for the delivery of an anticancer drug.

Tumor tissues of the xenograft PC-3 tumor model were observed with a confocal laser scanning microscope (Leica, Wetzlar, Germany). Microbubbles with doxorubicin (DOX; Sigma-Aldrich, St. Louis, MO, USA) were injected via the tail vein, and then ultrasound treatment for delivery was performed using a sonoporator (Sonidel, Dublin, Ireland) equipped with a $1-\mathrm{MHz}$ probe. The parameters of the ultrasound machine were $2 \mathrm{w} / \mathrm{cm}^{2}, 60 \%$ of the duty cycle, and 5 minutes (A), 10 minutes (B), and 15 minutes (C) in three different trials, respectively. By changing the treatment time from 5 minutes to 15 minutes, the proportion of the fluorescence intensity of DOX in tumor tissues increased (scale bars $=50 \mu \mathrm{m}$ ).

\section{of doxorubicin in tumor tissues.}

Recently, in addition to drug delivery, new therapeutic methods have been introduced for treating prostate cancer, including RNA interference (RNAi). RNAi relies on post-transcriptional gene silencing using double-strand RNA processed into strands of 21 25 nucleotides, known as small interfering RNA (siRNA) [72]. New targeted gene therapy using RNAi is being investigated for the treatment of prostate cancer. siRNA promotes targeted gene silencing by the sequence-specific degradation of messenger RNA when it is incorporated into RNA-induced silencing complexes in the cytoplasm $[72,73]$. Since siRNA can prevent the production of specific proteins essential for the proliferation of tumor cells, it is a promising therapeutic approach for cancer treatment. 


\section{Conclusion}

One of the most common modalities used in prostate imaging is transrectal ultrasonography. The role of ultrasonography in evaluating the prostate may no longer be limited to imaging, but may expand to incorporate image-guided therapy using microbubbles. Several targeting strategies are being researched, with a focus on many specific ligands, including PSMA, integrin, VEGFR2, and HER2, which may be promising examples of targeting. Ultrasound molecular imaging has just started its long journey from in vitro and in vivo preclinical studies to the first human clinical trials. Of particular note, the safety and convenience of ultrasound make it an attractive imaging modality for clinical applications. Ultrasound-mediated delivery has other advantages, such as the simultaneous delivery of anti-cancer drugs and genetic therapeutics. The use of ultrasound and microbubble complexes containing genetic therapeutics and chemotherapeutic agents creates the possibility of clinically applicable image-guided therapy and provides novel prospects for therapeutic applications in the near future.

ORCID: Hak Jong Lee: http://orcid.org/0000-0003-0858-7873; Young II Yoon: http:// orcid.org/0000-0001-9957-4896; Yun Jung Bae: http://orcid.org/0000-0002-17794949

\section{Conflict of Interest}

No potential conflict of interest relevant to this article was reported.

\section{Acknowledgments}

This research was supported by grant number NRF-2015R1D1A1A09 056744.

\section{References}

1. Wilson SR, Burns PN. Microbubble-enhanced US in body imaging: what role? Radiology 2010;257:24-39.

2. Pysz MA, Willmann JK. Targeted contrast-enhanced ultrasound: an emerging technology in abdominal and pelvic imaging. Gastroenterology 2011;140:785-790.

3. Kiessling F, Fokong S, Bzyl J, Lederle W, Palmowski M, Lammers T. Recent advances in molecular, multimodal and theranostic ultrasound imaging. Adv Drug Deliv Rev 2014;72:15-27.

4. Abou-Elkacem L, Bachawal SV, Willmann JK. Ultrasound molecular imaging: moving toward clinical translation. Eur J Radiol 2015;84:1685-1693.

5. Hwang SI, Lee HJ. The future perspectives in transrectal prostate ultrasound guided biopsy. Prostate Int 2014;2:153-160.

6. Yoon YI, Kwon YS, Cho HS, Heo SH, Park KS, Park SG, et al. Ultrasound-mediated gene and drug delivery using a microbubble- liposome particle system. Theranostics 2014;4:1133-1144.

7. Moon H, Yoon C, Lee TW, Ha KS, Chang JH, Song TK, et al. Therapeutic ultrasound contrast agents for the enhancement of tumor diagnosis and tumor therapy. J Biomed Nanotechnol 2015;11:1183-1192.

8. Wang X, Liang HD, Dong B, Lu QL, Blomley MJ. Gene transfer with microbubble ultrasound and plasmid DNA into skeletal muscle of mice: comparison between commercially available microbubble contrast agents. Radiology 2005;237:224-229.

9. Blomley MJ, Cooke JC, Unger EC, Monaghan MJ, Cosgrove DO. Microbubble contrast agents: a new era in ultrasound. BMJ 2001;322:1222-1225

10. Hernot $S$, Klibanov AL. Microbubbles in ultrasound-triggered drug and gene delivery. Adv Drug Deliv Rev 2008;60:1153-1166.

11. Wu Y, Unger EC, McCreery TP, Sweitzer RH, Shen D, Wu G, et al. Binding and lysing of blood clots using MRX-408. Invest Radiol 1998:33:880-885.

12. Willmann JK, Cheng Z, Davis C, Lutz AM, Schipper ML, Nielsen $\mathrm{CH}$, et al. Targeted microbubbles for imaging tumor angiogenesis: assessment of whole-body biodistribution with dynamic micro-PET in mice. Radiology 2008;249:212-219.

13. Klibanov AL, Rasche PT, Hughes MS, Wojdyla JK, Galen KP, Wible JH $\mathrm{Jr}$, et al. Detection of individual microbubbles of ultrasound contrast agents: imaging of free-floating and targeted bubbles. Invest Radio 2004;39:187-195.

14. Deshpande N, Needles A, Willmann JK. Molecular ultrasound imaging: current status and future directions. Clin Radiol 2010:65:567-581.

15. Maeda H. The enhanced permeability and retention (EPR) effect in tumor vasculature: the key role of tumor-selective macromolecular drug targeting. Adv Enzyme Regul 2001;41:189-207.

16. Maeda H, Sawa T, Konno T. Mechanism of tumor-targeted delivery of macromolecular drugs, including the EPR effect in solid tumor and clinical overview of the prototype polymeric drug SMANCS. J Control Release 2001;74:47-61.

17. Lanza GM, Moonen C, Baker JR Jr, Chang E, Cheng Z, Grodzinski $P$, et al. Assessing the barriers to image-guided drug delivery. Wiley Interdiscip Rev Nanomed Nanobiotechnol 2014;6:1-14.

18. Armstrong JK, Hempel G, Koling S, Chan LS, Fisher T, Meiselman HJ, et al. Antibody against poly (ethylene glycol) adversely affects PEGasparaginase therapy in acute lymphoblastic leukemia patients. Cancer 2007;110:103-111.

19. Kaneko OF, Willmann JK. Ultrasound for molecular imaging and therapy in cancer. Quant Imaging Med Surg 2012;2:87-97.

20. Pochon S, Tardy I, Bussat P, Bettinger T, Brochot J, von Wronski $M$, et al. BR55: a lipopeptide-based VEGFR2-targeted ultrasound contrast agent for molecular imaging of angiogenesis. Invest Radio 2010;45:89-95.

21. Pysz MA, Foygel K, Rosenberg J, Gambhir SS, Schneider M, 
Willmann JK. Antiangiogenic cancer therapy: monitoring with molecular US and a clinically translatable contrast agent (BR55). Radiology 2010;256:519-527.

22. Silver DA, Pellicer I, Fair WR, Heston WD, Cordon-Cardo C. Prostatespecific membrane antigen expression in normal and malignant human tissues. Clin Cancer Res 1997;3:81-85.

23. Lapidus RG, Tiffany CW, Isaacs JT, Slusher BS. Prostate-specific membrane antigen (PSMA) enzyme activity is elevated in prostate cancer cells. Prostate 2000;45:350-354.

24. Ross JS, Sheehan CE, Fisher HA, Kaufman RP Jr, Kaur P, Gray K, et al. Correlation of primary tumor prostate-specific membrane antigen expression with disease recurrence in prostate cancer. Clin Cancer Res 2003;9:6357-6362.

25. Tasch J, Gong M, Sadelain M, Heston WD. A unique folate hydrolase, prostate-specific membrane antigen (PSMA): a target for immunotherapy? Crit Rev Immunol 2001;21:249-261.

26. Chang SS, Reuter VE, Heston WD, Bander NH, Grauer LS, Gaudin PB. Five different anti-prostate-specific membrane antigen (PSMA) antibodies confirm PSMA expression in tumor-associated neovasculature. Cancer Res 1999;59:3192-3198.

27. Maresca KP, Hillier SM, Femia FJ, Keith D, Barone C, Joyal JL, et al. A series of halogenated heterodimeric inhibitors of prostate specific membrane antigen (PSMA) as radiolabeled probes for targeting prostate cancer. J Med Chem 2009;52:347-357.

28. Murphy GP, Elgamal AA, Su SL, Bostwick DG, Holmes EH. Current evaluation of the tissue localization and diagnostic utility of prostate specific membrane antigen. Cancer 1998;83:2259-2269.

29. Nawaz S. A new gallium-68 labelled imaging agent for prostate cancer. PhD dissertation. London: King's College, 2013.

30. Henry MD, Wen S, Silva MD, Chandra S, Milton M, Worland PJ. A prostate-specific membrane antigen-targeted monoclonal antibodychemotherapeutic conjugate designed for the treatment of prostate cancer. Cancer Res 2004;64:7995-8001.

31. Milowsky MI, Nanus DM, Kostakoglu L, Vallabhajosula S, Goldsmith SJ, Bander NH. Phase I trial of yttrium-90-labeled anti-prostatespecific membrane antigen monoclonal antibody J591 for androgen-independent prostate cancer. J Clin Oncol 2004;22:25222531.

32. Kuroda K, Liu H, Kim S, Guo M, Navarro V, Bander NH. Saporin toxin-conjugated monoclonal antibody targeting prostatespecific membrane antigen has potent anticancer activity. Prostate 2010;70:1286-1294.

33. Kim CH, Axup JY, Lawson BR, Yun H, Tardif V, Choi SH, et al. Bispecific small molecule-antibody conjugate targeting prostate cancer. Proc Natl Acad Sci U S A 2013;110:17796-17801.

34. Friedrich SW, Lin SC, Stoll BR, Baxter LT, Munn LL, Jain RK. Antibodydirected effector cell therapy of tumors: analysis and optimization using a physiologically based pharmacokinetic model. Neoplasia 2002:4:449-463.
35. Maloney DG, Grillo-Lopez AJ, Bodkin DJ, White CA, Liles TM, Royston I, et al. IDEC-C2B8: results of a phase I multiple-dose trial in patients with relapsed non-Hodgkin's lymphoma. J Clin Oncol 1997; 15:3266-3274.

36. Jain RK. Physiological barriers to delivery of monoclonal antibodies and other macromolecules in tumors. Cancer Res 1990;50 (3 Suppl):814s-819s.

37. Krall N, Scheuermann J, Neri D. Small targeted cytotoxics: current state and promises from DNA-encoded chemical libraries. Angew Chem Int Ed Engl 2013;52:1384-1402.

38. Kularatne SA, Wang K, Santhapuram HK, Low PS. Prostate-specific membrane antigen targeted imaging and therapy of prostate cancer using a PSMA inhibitor as a homing ligand. Mol Pharm 2009;6:780-789.

39. Zhou J, Neale JH, Pomper MG, Kozikowski AP. NAAG peptidase inhibitors and their potential for diagnosis and therapy. Nat Rev Drug Discov 2005;4:1015-1026.

40. Chen Y, Foss CA, Byun Y, Nimmagadda S, Pullambhatla M, Fox JJ, et al. Radiohalogenated prostate-specific membrane antigen (PSMA)based ureas as imaging agents for prostate cancer. J Med Chem 2008;51:7933-7943.

41. Malmberg J, Tolmachev V, Orlova A. Imaging agents for in vivo molecular profiling of disseminated prostate cancer: Cellular processing of [(111)In]-labeled CHX-A"DTPA-trastuzumab and anti-HER2 ABY-025 Affibody in prostate cancer cell lines. Exp Ther Med 2011;2:523-528.

42. Desgrosellier JS, Cheresh DA. Integrins in cancer: biological implications and therapeutic opportunities. Nat Rev Cancer 2010;10:9-22.

43. McCabe NP, De S, Vasanji A, Brainard J, Byzova TV. Prostate cancer specific integrin alphavbeta3 modulates bone metastatic growth and tissue remodeling. Oncogene 2007;26:6238-6243.

44. Wang F, Chen L, Zhang R, Chen Z, Zhu L. RGD peptide conjugated liposomal drug delivery system for enhance therapeutic efficacy in treating bone metastasis from prostate cancer. J Control Release 2014; 196:222-233.

45. Schneider JG, Amend SR, Weilbaecher KN. Integrins and bone metastasis: integrating tumor cell and stromal cell interactions. Bone 2011;48:54-65.

46. Bakewell SJ, Nestor P, Prasad S, Tomasson MH, Dowland $N_{1}$ Mehrotra $M$, et al. Platelet and osteoclast beta3 integrins are critical for bone metastasis. Proc Natl Acad Sci U S A 2003;100:14205-14210.

47. Accardo A, Tesauro D, Morelli G. Peptide-based targeting strategies for simultaneous imaging and therapy with nanovectors. Polym J 2013;45:481-493.

48. Levine RM, Scott CM, Kokkoli E. Peptide functionalized nanoparticles for nonviral gene delivery. Soft Matter 2013;9:9851004. 
49. Cui L, Liu Z, Jin X, Jia B, Li F, Wang F. Evaluation of 188Re-MAG2RGD-bombesin for potential prostate cancer therapy. Nucl Med Biol 2013:40:182-189.

50. Schottelius M, Laufer B, Kessler H, Wester HJ. Ligands for mapping alphavbeta3-integrin expression in vivo. Acc Chem Res 2009:42:969-980.

51. Liu S. Radiolabeled cyclic RGD peptides as integrin alpha(v)beta(3)targeted radiotracers: maximizing binding affinity via bivalency. Bioconjug Chem 2009;20:2199-2213.

52. Cai W, Niu G, Chen X. Imaging of integrins as biomarkers for tumor angiogenesis. Curr Pharm Des 2008;14:2943-2973.

53. Liu Z, Wang F, Chen X. Integrin targeted delivery of radiotherapeutics. Theranostics 2011;1:201-210.

54. Tachibana K, Tachibana S. The use of ultrasound for drug delivery. Echocardiography 2001;18:323-328.

55. Yuh EL, Shulman SG, Mehta SA, Xie J, Chen L, Frenkel V, et al. Delivery of systemic chemotherapeutic agent to tumors by using focused ultrasound: study in a murine model. Radiology 2005:234:431-437.

56. Bekeredjian R, Chen S, Grayburn PA, Shohet RV. Augmentation of cardiac protein delivery using ultrasound targeted microbubble destruction. Ultrasound Med Biol 2005;31:687-691.

57. De Temmerman ML, Dewitte H, Vandenbroucke RE, Lucas B, Libert C, Demeester J, et al. mRNA-Lipoplex loaded microbubble contrast agents for ultrasound-assisted transfection of dendritic cells. Biomaterials 2011;32:9128-9135.

58. Sirsi SR, Borden MA. State-of-the-art materials for ultrasoundtriggered drug delivery. Adv Drug Deliv Rev 2014;72:3-14.

59. De Cock I, Zagato E, Braeckmans K, Luan Y, de Jong N, De Smedt SC, et al. Ultrasound and microbubble mediated drug delivery: acoustic pressure as determinant for uptake via membrane pores or endocytosis. J Control Release 2015;197:20-28.

60. Stride E. Physical principles of microbubbles for ultrasound imaging and therapy. Cerebrovasc Dis 2009;27 Suppl 2:1-13.

61. Quaia E. Microbubble ultrasound contrast agents: an update. Eur Radiol 2007;17:1995-2008.

62. Lentacker I, De Cock I, Deckers R, De Smedt SC, Moonen CT.
Understanding ultrasound induced sonoporation: definitions and underlying mechanisms. Adv Drug Deliv Rev 2014;72:49-64.

63. Tachibana K, Uchida T, Ogawa K, Yamashita N, Tamura K. Induction of cell-membrane porosity by ultrasound. Lancet 1999;353:1409.

64. Kudo N, Okada K, Yamamoto K. Sonoporation by single-shot pulsed ultrasound with microbubbles adjacent to cells. Biophys J 2009;96:4866-4876.

65. van Wamel A, Kooiman K, Harteveld M, Emmer M, ten Cate $F J$, Versluis $M$, et al. Vibrating microbubbles poking individual cells: drug transfer into cells via sonoporation. J Control Release 2006;112:149-155.

66. Guzman HR, Nguyen DX, Khan S, Prausnitz MR. Ultrasoundmediated disruption of cell membranes. I. Quantification of molecular uptake and cell viability. J Acoust Soc Am 2001;110:588596.

67. Meijering BD, Juffermans LJ, van Wamel A, Henning RH, Zuhorn IS, Emmer $\mathrm{M}$, et al. Ultrasound and microbubble-targeted delivery of macromolecules is regulated by induction of endocytosis and pore formation. Circ Res 2009;104:679-687.

68. Afadzi M, Strand SP, Nilssen EA, Masoy SE, Johansen TF, Hansen R, et al. Mechanisms of the ultrasound-mediated intracellular delivery of liposomes and dextrans. IEEE Trans Ultrason Ferroelectr Freq Control 2013;60:21-33.

69. Hauser J, Ellisman M, Steinau HU, Stefan E, Dudda M, Hauser M. Ultrasound enhanced endocytotic activity of human fibroblasts. Ultrasound Med Biol 2009;35:2084-2092.

70. Lionetti V, Fittipaldi A, Agostini S, Giacca M, Recchia FA, Picano E. Enhanced caveolae-mediated endocytosis by diagnostic ultrasound in vitro. Ultrasound Med Biol 2009:35:136-143.

71. Paula DM, Valero-Lapchik VB, Paredes-Gamero EJ, Han SW. Therapeutic ultrasound promotes plasmid DNA uptake by clathrinmediated endocytosis. J Gene Med 2011;13:392-401.

72. Kawasaki H, Taira K, Morris KV. siRNA induced transcriptional gene silencing in mammalian cells. Cell Cycle 2005;4:442-448.

73. Barik S. Silence of the transcripts: RNA interference in medicine. J Mol Med (Berl) 2005:83:764-773. 